\title{
Preparation of calcium-phosphate cements with high compressive strength using meglumine as a water reducer
}

\author{
Takenori SAWAMURA, ${ }^{* * *, \dagger}$ Masahiko OKUYAMA, ${ }^{*}$ Hirotaka MAEDA, ${ }^{* *}$ \\ Akiko OBATA $^{* *}$ and Toshihiro KASUGA ${ }^{* *}$ \\ ${ }^{*}$ Engineering R \& D Group, NGK Spark Plug Co. Ltd., 2808 Iwasaki, Komaki, Aichi 485-8510, Japan \\ ***Nagoya Institute of Technology, Gokiso-cho, Showa-ku, Nagoya 4666-8555, Japan
}

Calcium phosphate cements (CPCs) were prepared using meglumine to evaluate the effect of reduced mixing liquid in a CPC paste on plasticity and compressive strength. Raw CPC powders prepared using tetracalcium phosphate and dicalcium phosphate anhydrous were mixed with distilled water, meglumine aqueous solution (MG), and meglumine containing citric acid aqueous solution, to produce CPC pastes. Pastes prepared using MG exhibited a large plasticity, despite the fact that only a small amount of liquid was used for mixing the raw CPC powders (liquid-to-powder ratio of $0.21 \mathrm{~g} \cdot \mathrm{g}^{-1}$ ). The compressive strengths and bulk densities of the CPC setting bodies increased with increasing MG concentration in the mixing liquid. CPC setting bodies prepared using 3 mass \% MG had a compressive strength greater than $80 \mathrm{MPa}$ after being soaked in simulated body fluid at $37^{\circ} \mathrm{C}$ for $24 \mathrm{~h}$. The high obtained compressive strength was attributed to a reduced amount of (large) voids in the CPC setting body owing to efficient CPC powder dispersion in the mixing liquid during preparation of the CPC paste as a result of MG adsorbed onto the surface of the CPC powder. Although the setting time of CPC pastes prepared using MG was longer than that using distilled water because of the delay of hydroxyapatite formation with hydration, CPC pastes prepared using meglumine that contained citric acid aqueous solution had a shorter setting time. The resulting CPCs showed an improved performance for clinical application, that is, high compressive strength and adequate setting time.

(2016 The Ceramic Society of Japan. All rights reserved.

Key-words : Calcium phosphate cement, Meglumine, Compressive strength, Setting time, Hydration

[Received October 24, 2015; Accepted December 18, 2015]

\section{Introduction}

Calcium phosphate cements (CPCs) have been used as bone substitutes in clinical applications ${ }^{1), 2)}$ because the formability and injectability of CPC pastes prepared by mixing calcium phosphate powders with liquid are advantageous for filling bone defects. CPCs show biocompatibility and osteoconductivity after implantation in the body because of setting behavior with conversion to hydroxyapatite (HA) through hydration. ${ }^{3)}$ Ideally, CPCs should exhibit rapid high strength for early ambulation and application in high loaded areas such as femurs and vertebrae.4),5) Bone cement that consists of polymethylmethacrylate reaches a compressive strength of more than $70 \mathrm{MPa}$ after setting, and has been used in total hip replacements and vertebroplasty in orthopedics. ${ }^{6,7)}$ However, CPCs, which have been applied in clinical fields, show a compressive strength of $<50 \mathrm{MPa}$ after $24 \mathrm{~h},{ }^{8), 9)}$ which is insufficient for bone repair in loaded areas.

Some reports exist on the addition of $\mathrm{TiO}_{2}$, carbon fiber, and organic fiber into CPCs and compression during filling in a mold to improve their mechanical properties. ${ }^{10)-13)}$ When CPC paste is obtained by mixing CPC powders with liquid, minimal liquid is needed in the hydration reaction and most liquid in the CPC mixing contributes to maintain the formability and workability of the CPC paste. Excessive mixing liquid induces some voids in the CPC setting body and results in a decrease in its bulk density. A reduction in the amount of liquid added for CPC mixing is effective for improving the compressive strength of CPCs. ${ }^{14)}$ In

Corresponding author: T. Sawamura; E-mail: t-sawamura@mg. ngkntk.co.jp our previous work, raw CPC powders prepared using agglomerated dicalcium phosphate anhydrous particles consisting of fine primary particles showed a high packing density and good performance of the resulting CPC pastes in a lower amount of liquid. ${ }^{15)}$ The compressive strength of the CPC increased with increasing initial setting temperatures. ${ }^{16)}$

Industrial cements and concretes, which show setting behavior by hydration and CPCs, exhibited an improved compressive strength by dispersant addition as a water reducer, maintained workability in a small amount of liquid for mixing, and resulted in a high compressive strength that depended on the increasing bulk density of the setting body. ${ }^{17), 18)}$ In general, fine particles agglomerate easily and form secondary particles by adhesion and interparticle force agglomeration. ${ }^{19)}$ Dispersants control particle approach and stabilize particle dispersion in suspension because of dispersant adsorption on the particle surface by steric hindrance and electrostatic repulsion. ${ }^{20)}$ Polyacrylate is a type of dispersant that is able to provide steric hindrance between particles, ${ }^{21)}$ and it was reported that the addition of ammonium polyacrylate to CPC reduced the amount of liquid required for mixing; however, the compressive strength was lower than the bone cement. ${ }^{22)}$

The addition of meglumine $\left[\mathrm{CH}_{3} \mathrm{NHCH}_{2}(\mathrm{CHOH})_{4} \mathrm{CH}_{2} \mathrm{OH}\right.$, CAS No. 6284-40-8], which is a type of aminoalcohol, into CPC, is expected to result in the generation of electrostatic repulsion between CPC particles because of the adsorption of its hydroxyl group on their surface and the coordination of $\mathrm{H}^{+}$to its amino group. Thus, meglumine is expected to improve the dispersion of CPC powder during preparation of CPC pastes. This mechanism may lead to a reduction in the amount of liquid required for $\mathrm{CPC}$ 
mixing and a high compressive strength of the CPC setting body caused by an increase in bulk density to remove some voids. In addition, if CPC powder could be dispersed well by adding a small amount of meglumine, the biocompatibility and bioactivity of CPC would not be degraded. Meglumine has been applied as a solubilizing agent for contrast media in diagnostic imaging, has been verified as safe for the living body, ${ }^{23), 24)}$ and will be suitable for CPC implanted into bone.

In this work, $\mathrm{CPCs}$ were prepared using meglumine as a water reducer. Because meglumine aqueous solution has a high $\mathrm{pH}$, it may retard the setting reaction of CPC with hydration, which results in neutral HA formation. Therefore, citric acid, which accelerates CPC setting, ${ }^{25)}$ was added to $\mathrm{CPC}$ with meglumine. The objective of this work was to prepare CPC that exhibits a high compressive strength and good formability using a small amount of mixing liquid with meglumine.

\section{Experimental procedure}

Dicalcium phosphate anhydrous (DCPA; $\mathrm{CaHPO}_{4}$, Taihei Chemical Industrial, Nara, Japan; mean particle size $8.0 \mu \mathrm{m}$ ) was milled with distilled water for $24 \mathrm{~h}$ using an alumina ball mill, and dried at $120^{\circ} \mathrm{C}$ for $20 \mathrm{~h}$ following our previous work. ${ }^{15)}$ The resulting DCPA sample had a mean particle size of $0.6 \mu \mathrm{m}$ using the intercept method, and referring to the international standard ISO 13383-2012 for fine ceramics (Microstructural characterization - Part 1: Determination of grain size and size distribution). Tetracalcium phosphate [TeCP; $\left.\mathrm{Ca}_{4}\left(\mathrm{PO}_{4}\right)_{2} \mathrm{O}\right]$ was prepared as follows: a mixture consisting of dihydrous dicalcium phosphate $\left(\mathrm{CaHPO}_{4} \cdot 2 \mathrm{H}_{2} \mathrm{O}\right.$; Kanto Kagaku, Tokyo, Japan) and calcium carbonate $\left(\mathrm{CaCO}_{3} ;\right.$ Kanto Kagaku, Tokyo, Japan) at a weight ratio of $1.75: 1$ was fired at $1550^{\circ} \mathrm{C}$ for $10 \mathrm{~h}$ and then quenched at room temperature. The resulting matter was crushed to prepare powders with an average particle size of $200 \mu \mathrm{m}$. The raw CPC powders were prepared by mixing $67.5 \mathrm{~g}$ TeCP and $32.5 \mathrm{~g}$ DCPA using an automatic mortar. Distilled water (DW), 1-3 mass \% meglumine $\left(\mathrm{C}_{7} \mathrm{H}_{17} \mathrm{NO}_{5}\right.$; Wako Pure Chemical Industries, Osaka, Japan) aqueous solutions (MG), or a 3 mass $\% \mathrm{MG}$ and 2 mass $\%$ citric acid $\left(\mathrm{C}_{6} \mathrm{H}_{8} \mathrm{O}_{7}\right.$; Wako Pure Chemical Industries, Osaka, Japan) aqueous solution (MG/CA), for which the initial concentration was determined, were used as mixing liquids. Raw CPC powders were mixed with DW at a liquid-to-powder ratio $\left(\mathrm{L} / \mathrm{P} ; \mathrm{g} \cdot \mathrm{g}^{-1}\right)$ of 0.25 , as described in our previous report, ${ }^{15)}$ or with mixing liquid added to meglumine at a $\mathrm{L} / \mathrm{P}$ of 0.21 to evaluate water reduction effects for 1 min using a spatula and a glass dish to prepare the CPC paste.

To measure the plasticity of the resulting CPC paste, the molded CPC paste $(9 \mathrm{~mm}$ diameter, $10 \mathrm{~mm}$ height) was compressed under a load of $0.14 \mathrm{MPa}$ for $2 \mathrm{~min}$ after onset of the mixing liquid. Plasticity was calculated from the diameter of the CPC paste, using the following equation $(n=5)$ :

$$
\text { Plasticity value }(\%)=(b-a) / a \times 100,
$$

where $a$ and $b$ are the diameter of the CPC paste before and after compression, respectively.

To measure the setting time, the CPC paste was used to fill the void in a stainless steel ring ( $10 \mathrm{~mm}$ inner diameter, $5 \mathrm{~mm}$ height $)$ and flattened on its top surface. A vicker needle $\left(300 \mathrm{~g}, 1 \mathrm{~mm}^{2}\right.$ cross-sectional area) was set on the top surface of the filled $\mathrm{CPC}$ paste at $37^{\circ} \mathrm{C}$ and $95 \%$ relative humidity. The setting time was determined as the time at which no dent was formed by the needle $(n=5)$.

The CPC paste was molded into disks of $6 \mathrm{~mm}$ diameter and $12 \mathrm{~mm}$ height, removed from the disk after being maintained at $37^{\circ} \mathrm{C}$ and $95 \%$ relative humidity for $1 \mathrm{~h}$, and soaked in simulated body fluid $(\mathrm{SBF})^{26), 27)}$ at $37^{\circ} \mathrm{C}$ for $24 \mathrm{~h}$. The compressive strength of the CPC setting bodies after SBF soaking was evaluated using a Universal Testing Machine (Autograph AGS-5kND; Shimadzu, Kyoto, Japan). For measurement of the bulk density, identification of crystalline phase by X-ray diffraction and observation of the microstructure, CPC setting bodies after SBF soaking were soaked immediately in acetone for $1 \mathrm{~h}$ and dried under vacuum for $24 \mathrm{~h}$. The bulk density of the CPC setting bodies was calculated from the weight and volume $(n=5)$ :

$$
\text { Bulk density } / \mathrm{kg} \cdot \mathrm{m}^{-3}=4 \mathrm{~W} / \pi r^{2} h,
$$

where $W$ is the weight, $r$ is the diameter and $h$ is the height of the CPC setting body.

To evaluate the crystalline phase change during SBF soaking, the crystalline phase of dry ground fine powders of the CPC powder and setting bodies after SBF soaking for 10-24h was identified by X-ray diffraction (XRD; RU-200; Rigaku, Tokyo, Japan). The relative intensity of the HA phase was calculated from XRD patterns using:

$$
\begin{aligned}
& \text { Relative intensity of } \mathrm{HA}(\%) \\
& \quad=\left[I_{\mathrm{HA}} /\left(I_{\mathrm{DCPA}}+I_{\mathrm{TeCP}}+I_{\mathrm{HA}}\right)\right] \times 100 \\
& I_{\mathrm{DCPA}}: \text { Intensity of } \mathrm{DCPA}(020), 2 \theta=26.4^{\circ} \\
& I_{\mathrm{TeCP}}: \text { Intensity of } \mathrm{TeCP}(200), 2 \theta=25.3^{\circ} \\
& I_{\mathrm{HA}}: \text { Intensity of } \mathrm{HA}(002), 2 \theta=25.9^{\circ}
\end{aligned}
$$

Their diffraction peaks were selected for quantitative analysis, since they were isolated ones, that is, they did not overlap one another. The fracture surfaces of the dry samples after setting for $24 \mathrm{~h}$ were observed by scanning electron microscopy (SEM; VE8800; Keyence, Osaka, Japan). A 5 mass \% suspension of TeCP and DCPA was passed through a $106-\mu \mathrm{m}$ sieve of DW, or a 3 mass \% MG solution was prepared and the zeta potential and $\mathrm{pH}$ values in each suspension after stirring for $1 \mathrm{~min}$ were evaluated by acoustic and electroacoustic spectrometry (DT-1200, Dispersion Technology, New York, NY, USA). The particle size of TeCP and DCPA after sieving was measured using a laser diffraction particle distribution analyzer (LA-500; Horiba, Japan) after each particle was homogenized using an ultrasonic homogenizer in ethanol.

\section{Results}

\subsection{CPC mixed with meglumine}

In this work, 1-3 mass \% MGs were used as mixing liquids because CPC pastes containing $>3$ mass \% MG didn't set in our preliminary work.

Figure 1 shows the plasticity of the CPC pastes as a function of $\mathrm{MG}$ concentration in the mixing liquid. The plasticity value increases with increasing MG concentration. CPC pastes mixed with 3 mass \% MG showed a high plasticity value of $180 \%$ and it was confirmed visually that the resulting CPC paste had a good formability.

Figure 2 shows the compressive strength of CPC setting bodies after SBF soaking as a function of MG concentration in the mixing liquid. The compressive strength increases with increasing $\mathrm{MG}$ concentration and was $83.1 \mathrm{MPa}$ for the CPC setting bodies prepared using 3 mass \% MG.

Figure 3 shows the bulk density of CPC setting bodies as a function of mixing liquid MG concentration. The bulk density increases with increasing MG concentration.

The compressive strength of CPC setting bodies as a function of the bulk density of CPC setting bodies is shown in Fig. 4. The compressive strength increases with increasing bulk density. 


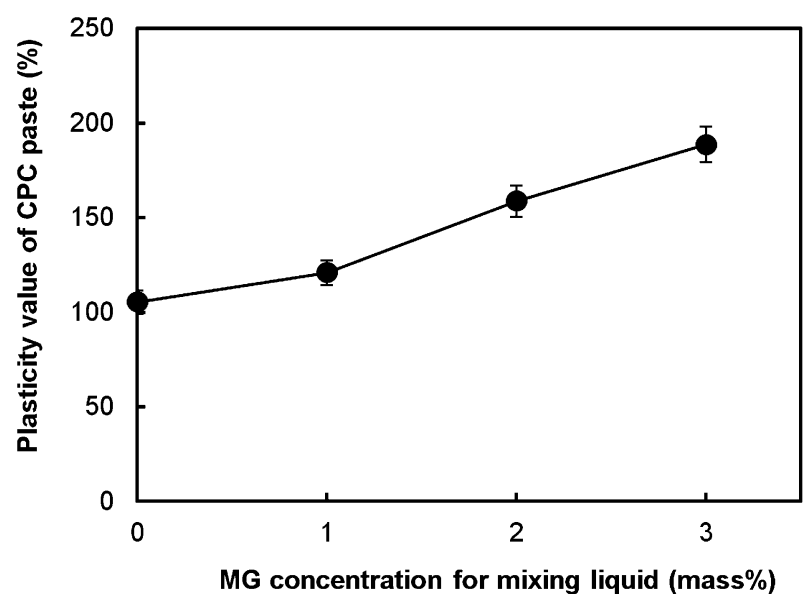

Fig. 1. Plasticity values of $\mathrm{CPC}$ pastes as a function of MG concentration for mixing liquid; data represent average values with associated standard deviations obtained from five measurements.

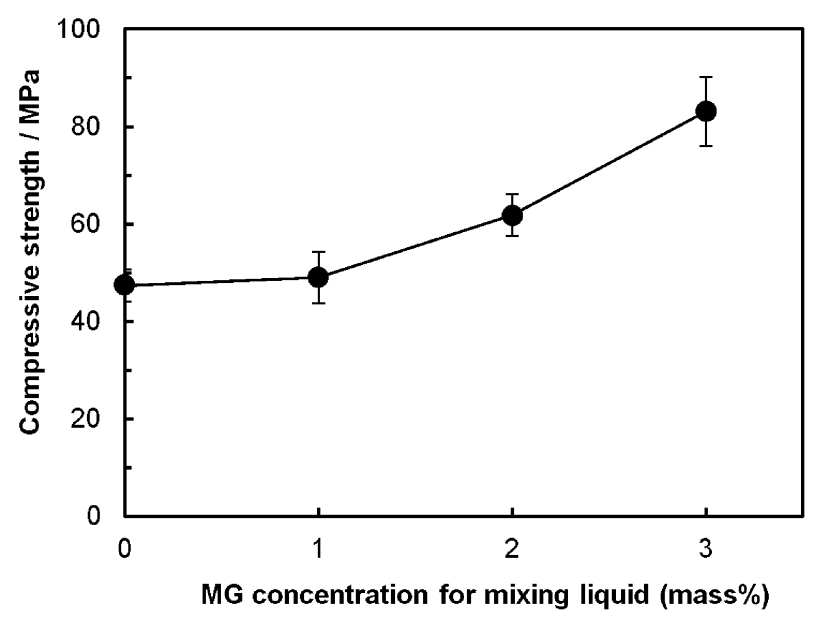

Fig. 2. Compressive strengths of CPC setting bodies after SBF soaking at $37^{\circ} \mathrm{C}$ for $24 \mathrm{~h}$ as a function of MG mixing liquid concentration; data represent average values with associated standard deviations obtained from five measurements.

Figure 5 shows the XRD patterns of the CPC setting bodies mixed with DW and 3 mass \% MG. In the setting bodies mixed with DW, HA peaks appeared after SBF soaking for $4 \mathrm{~h}$. These increased with time, and were accompanied by a decrease in intensity of the TeCP and DCPA peaks. In contrast, HA peaks were not visible after SBF soaking for $4 \mathrm{~h}$, and appeared after SBF soaking for $10 \mathrm{~h}$. This was accompanied by a decrease in TeCP and DCPA peak intensity and increased for $24 \mathrm{~h}$ in the setting bodies mixed with 3 mass $\%$ MG.

Figure 6 shows the relative intensity of HA in XRD spectra as a function of soaking time in SBF. The relative intensity of HA in the CPC setting bodies mixed with DW is higher than that of the CPC setting bodies mixed with MG after SBF soaking for $4 \mathrm{~h}$ and this difference was maintained after SBF soaking for 10 and $24 \mathrm{~h}$.

Table 1 shows the zeta potentials and $\mathrm{pH}$ values of suspensions of TeCP and DCPA, which are CPC powder components. DCPA and TeCP in DW were negatively charged at -6.5 and $-11.6 \mathrm{mV}$ zeta potentials. The absolute zeta potential values for DCPA and TeCP in MG were larger than in DW and especially that of DCPA is $-30.8 \mathrm{mV}$, which is approximately five times that in DW. The $\mathrm{pH}$ of the DCPA suspension in DW is 7.0 and

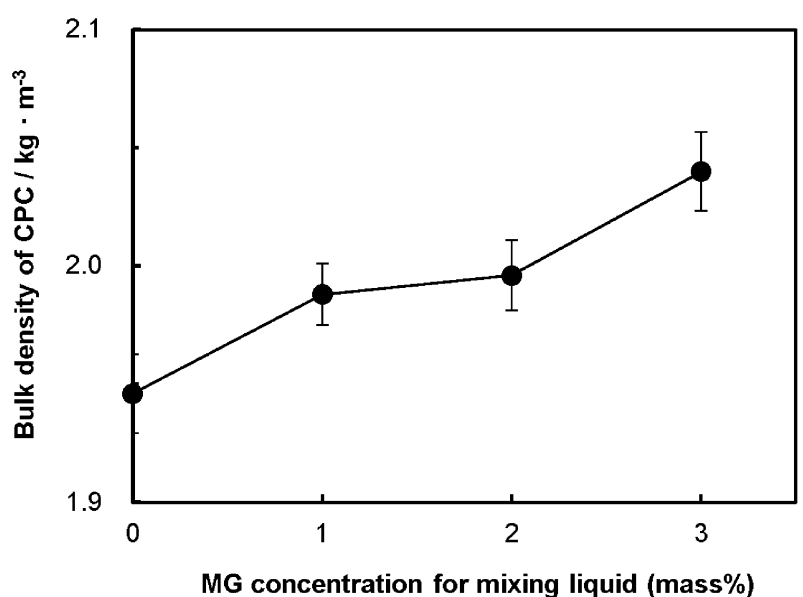

Fig. 3. Bulk densities of the CPC setting bodies after SBF soaking at $37^{\circ} \mathrm{C}$ for $24 \mathrm{~h}$ as a function of $\mathrm{MG}$ concentration for mixing liquid; data represent average values with associated standard deviations obtained from five measurements.

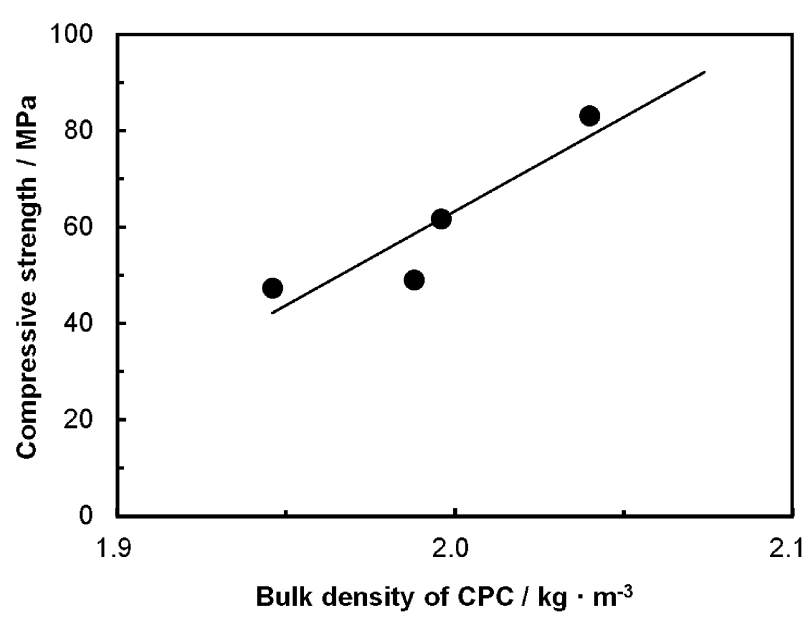

Fig. 4. Compressive strengths as a function of bulk densities of the CPC setting bodies after SBF soaking at $37^{\circ} \mathrm{C}$ for $24 \mathrm{~h}$.

that of the TeCP suspension is 10.3 , whereas that in $\mathrm{MG}$ is greater than 11.0.

\subsection{CPC mixed with meglumine and citric acid}

Two mass $\%$ of citric acid for mixing liquid was determined by our preliminary work; the setting time of CPC paste was prolonged by addition of 3 mass $\% \mathrm{MG}$ with 1 mass $\%$ citric acid aqueous solution, while it was drastically shorten by addition of 2 mass $\%$ citric acid.

Figure 7 shows the setting time of $\mathrm{CPC}$ pastes mixed with DW, 3 mass \% MG and MG/CA. Although the setting time of CPC pastes mixed with 3 mass $\%$ MG is delayed considerably compared with that with DW, the setting time is shortened by the addition of citric acid and was approximately $20 \mathrm{~min}$, which is sufficient for clinical use.

Figure 8 shows the compressive strength of CPC setting bodies mixed with each liquid. The high compressive strength of CPC setting bodies prepared using MG was maintained regardless of citric acid addition.

SEM images of fracture surfaces of the CPC setting bodies are shown in Fig. 9. Some voids of several tens of micrometers were 

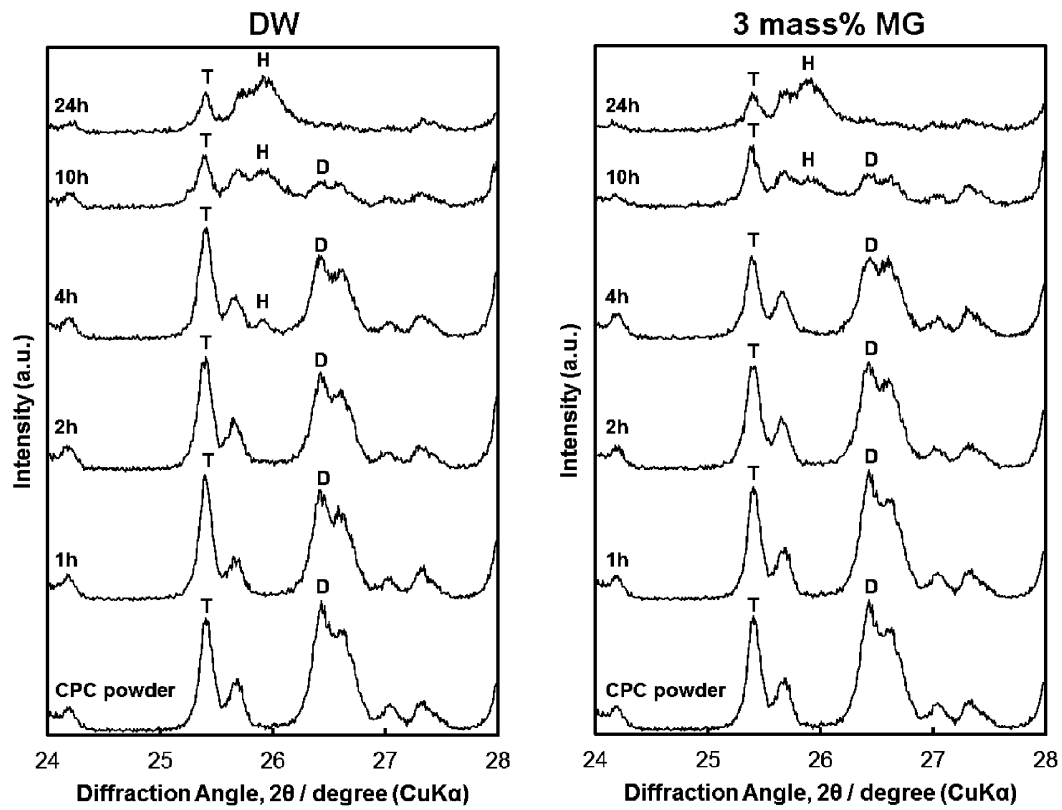

Fig. 5. X-ray diffraction patterns of $\mathrm{CPC}$ powders and $\mathrm{CPC}$ setting bodies after $\mathrm{SBF}$ soaking at $37^{\circ} \mathrm{C}$ for times shown on the left side, and mixing with DW and 3 mass \% MG; (H) HA, (T) TeCP, (D) DCPA.

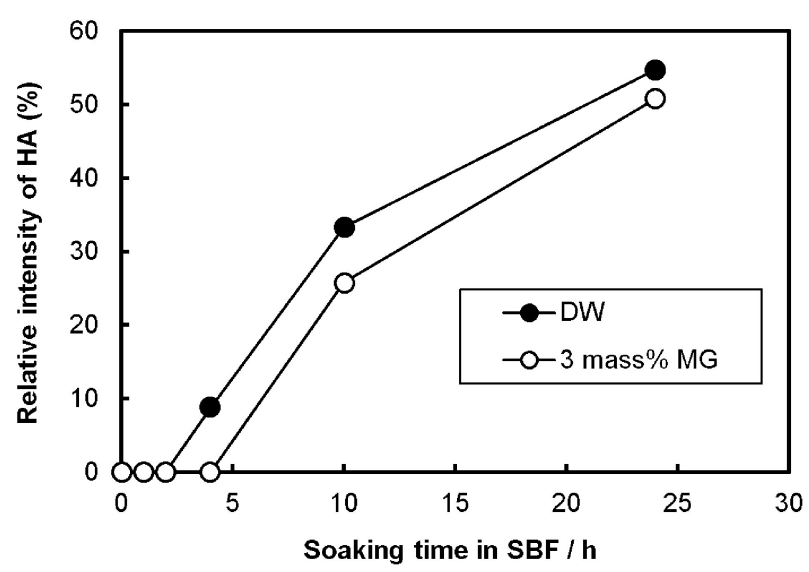

Fig. 6. Relative intensities of HA in XRD patterns of CPC setting bodies mixed with DW and 3 mass \% MG as a function of soaking time in SBF at $37^{\circ} \mathrm{C}$.

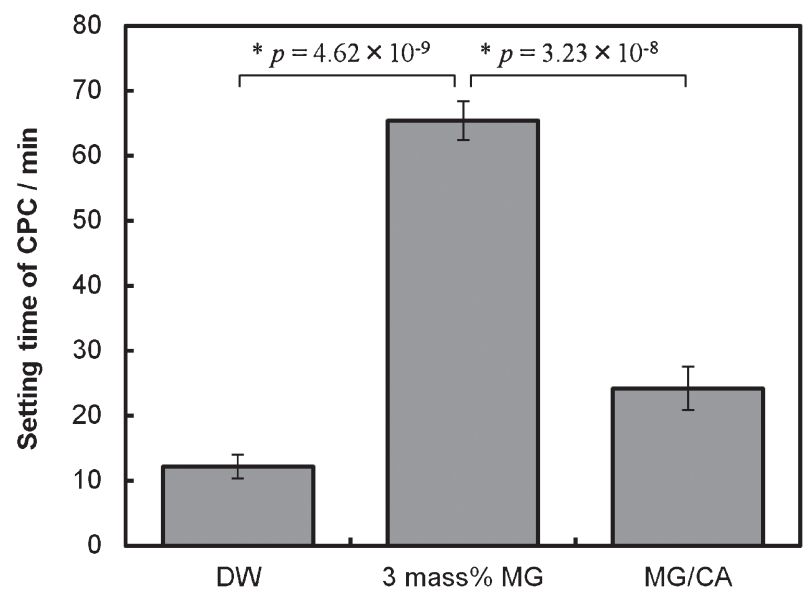

Fig. 7. Setting time of CPC pastes mixed with DW, 3 mass \% MG, and $\mathrm{MG} / \mathrm{CA}$. Data represent average values with associated standard deviations obtained from five measurements. Significant differences by Student's $t$-test were established as follows: ${ }^{*} p<0.05$.
Table 1. Zeta potentials and $\mathrm{pH}$ of $\mathrm{CPC}$ powder components; $\mathrm{TeCP}$ and DCPA in DW and 3 mass \% MG

\begin{tabular}{cccc}
\hline & Compound & DW & 3 mass \% MG \\
\hline Zeta-potential $(\mathrm{mV})$ & DCPA & $-6.5 \pm 0.7$ & $-30.8 \pm 1.2$ \\
& TeCP & $-11.6 \pm 0.3$ & $-23.5 \pm 7.0$ \\
pH & DCPA & $7.0 \pm 0.04$ & $11.4 \pm 0.03$ \\
& TeCP & $10.3 \pm 0.03$ & $11.5 \pm 0.01$ \\
\hline
\end{tabular}

Data represent average values with associated standard deviations obtained from five measurements.

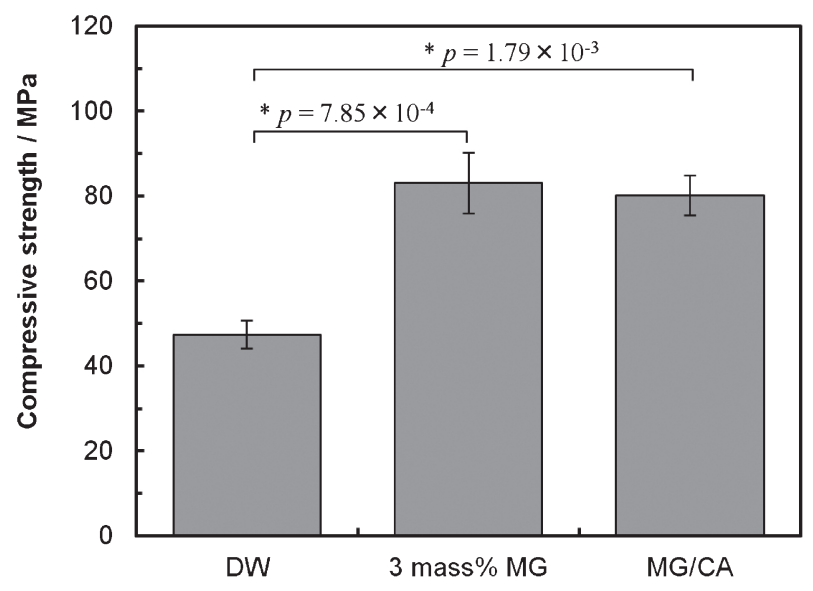

Fig. 8. Compressive strengths of CPC setting bodies after SBF soaking at $37^{\circ} \mathrm{C}$ for $24 \mathrm{~h}$, which was mixed with DW, 3 mass $\% \mathrm{MG}$, and MG/CA; data represent average values with associated standard deviations obtained from five measurements. Significant differences by Student's $t$-test was established as follows: ${ }^{*} p<0.05$.

observed in the CPC setting bodies mixed with DW. However, these were not observed for the mixing with 3 mass \% MG and $\mathrm{MG} / \mathrm{CA}$. 

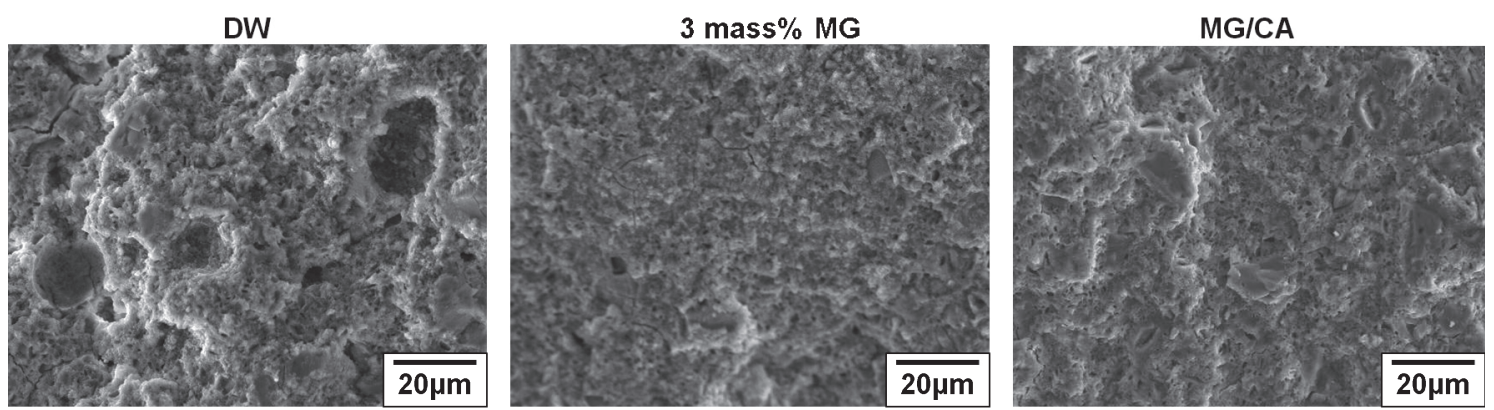

Fig. 9. SEM images of $\mathrm{CPC}$ setting bodies after $\mathrm{SBF}$ soaking at $37^{\circ} \mathrm{C}$ for $24 \mathrm{~h}$, and mixing with $\mathrm{DW}, 3$ mass $\%$ MG, and $\mathrm{MG} / \mathrm{CA}$.

\section{Discussion}

CPC pastes prepared using MG showed large plasticity values, even though they contained a small amount of liquid $(\mathrm{L} / \mathrm{P}=$ $0.21)$ compared with $\mathrm{CPC}$ pastes mixed with $\mathrm{DW}(\mathrm{L} / \mathrm{P}=0.25)$. The plasticity values increased with increasing MG concentration for the mixing liquid, as shown in Fig. 1. The viscosity, which corresponds to the plasticity value of the CPC pastes in this work, has been evaluated for ceramic dispersibility in slurry. ${ }^{28)}$ The increase in plasticity with increasing $\mathrm{MG}$ concentration most likely results from the dispersion effect by meglumine of $\mathrm{CPC}$ particles in CPC pastes. As shown in Table 1, the absolute values of zeta potential of DCPA and TeCP in MG were larger than those in DW and the zeta potential of DCPA was large compared with that of TeCP. In this evaluation, DCPA particles (D50 = $1.37 \mu \mathrm{m})$ were smaller than the $\mathrm{TeCP}$ particles $(40.5 \mu \mathrm{m})$ and therefore had a larger specific surface area compared with TeCP particles. The influence of zeta potential from meglumine increases in DCPA and DCPA in MG showed a zeta potential close to meglumine $(-34.2 \mathrm{mV}$ in the measured values), most likely because DCPA adsorbed a large amount of meglumine. The zeta potential became negative with increasing suspension $\mathrm{pH}^{28), 29)}$ The dispersion effect most likely resulted because of the increase in $\mathrm{pH}$, because the $\mathrm{pH}$ of the 3 mass $\% \mathrm{MG}$ was 11.4 and the suspension of DCPA and TeCP in 3 mass \% MG also showed high $\mathrm{pH}$ values.

The bulk densities of CPC setting bodies after SBF soaking for $24 \mathrm{~h}$ obtained by mixing with DW, 3 mass $\% \mathrm{MG}$, and MG/CA were $1.95,2.04$, and $2.07 \mathrm{~kg} \cdot \mathrm{m}^{-3}$ (measured values), respectively. Moreover, as shown in Fig. 9, any voids were not observed in the CPC setting bodies prepared using 3 mass $\%$ MG and MG/ $\mathrm{CA}$, although some voids existed in those mixed with DW. It is believed that a high compressive strength of the CPC setting bodies was achieved by increasing the bulk density because of the decreasing voids. The decrease in void amount resulted from the smaller amount of mixing liquid used, which was induced by the CPC paste mixing process, and was accompanied by an increase in plasticity values.

In this work, hydration of the CPC paste mixed with MG was delayed. It has been reported that $\mathrm{CPC}$ hydration is adequate under neutral conditions because of the dissolution of TeCP and DCPA and the supply of $\mathrm{Ca}^{+}$and $\mathrm{PO}_{4}{ }^{3-}$ ions to the mixing liquid to form $\mathrm{HA}$ in the CPC hydration mechanism. ${ }^{30)}$ However, the $\mathrm{pH}$ of the 3 mass \% MG was greater than 11.0 (i.e., alkaline), and the TeCP and DCPA solubility decreased under this condition. ${ }^{31)}$ The retardation of CPC hydration most likely resulted from the deficiency of $\mathrm{Ca}^{+}$and $\mathrm{PO}_{4}{ }^{3-}$ ions supplied from DCPA and TeCP to form HA by using MG as mixing liquid. However, HA formation was induced with increasing SBF soaking time even for CPC mixed with MG. This was likely because the $\mathrm{pH}$ shifts to a neutral value by the buffering action of the SBF. Accordingly, the dissolution of TeCP and DCPA could be accelerated, and calcium and phosphate ions could be supplied effectively to the mixing liquid to form HA while soaking in SBF. Sufficient HA formation after SBF soaking for $24 \mathrm{~h}$ resulted in a high compressive strength of the CPC setting bodies. It has been reported that the diametral tensile strength of CPC is dependent on the amount converted to HA. ${ }^{32)}$ In this work, the CPC prepared using MG showed a higher compressive strength than that using DW regardless of HA formation after SBF soaking for $24 \mathrm{~h}$. This most likely resulted from the decrease in voids and not the acceleration of HA formation, which may be the starting point for breakage. The setting time of the CPC pastes was shortened by the addition of citric acid into the mixing liquid, which may be caused by chelation with $\mathrm{Ca}^{+}$ions, ${ }^{25}$ ) and it is likely that an identical mechanism occurs in this work. CPCs mixed with MG/CA showed a shorter setting time and higher compressive strength.

\section{Conclusion}

CPCs were prepared using meglumine to evaluate the effects of compressive strength on the CPC setting bodies. CPC pastes mixed with MG showed high plasticities for smaller amounts of mixing liquid, and the compressive strength of these setting bodies increased with increasing MG concentration, which depended on an increase in bulk density. These may result from the dispersion of CPC powder caused by the absorption of meglumine on the CPC particle surface. The setting time of CPC pastes mixed with MG was longer than that with DW. This most likely occurred because of the delayed commencement of the hydration reaction, which resulted from the mixing condition with high MG pH. However, the setting time was shortened and adjusted by the addition of citric acid into the mixing liquid. As a result, CPCs prepared using meglumine showed excellent performance for clinical applications, with high compressive strength and adequate setting time.

\section{References}

1) M. Jeyam, J. G. Andrew, L. T. Muir and A. Mcgovern, J. Hand Surg. Eur, 27B, 146-149 (2002).

2) P. Lobenhoffer, T. Gerich, F. Witte and H. Tscherne, J. Orthop. Trauma, 16, 143-149 (2002).

3) G. Hannink, J. G. C. Wolke, B. W. Schreurs and P. Buma, J. Biomed. Mater. Res., 85B, 478-488 (2008).

4) P. Mattsson, A. Alberts, G. Dahlberg, M. Sohlman, H. C. Hyldahl and S. Larsson, J. Bone Joint Surg. Br., 87B, 12031209 (2005).

5) M. Nakano, N. Hirano, H. Ishihara, Y. Kawaguchi and K. Matsuura, J. Neurosurg. Spine, 2, 27-33 (2005).

6) K. D. Kuehn, W. Ege and U. Gopp, Orthop. Clin. North Am., 
36, 29-39 (2005).

7) M. Arora, E. K. S. Chan, S. Gupta and A. D. Diwan, World J. Orthop., 4, 67-74 (2013).

8) A. J. Ambard and L. Mueninghoff, Prostodont., 15, 321-328 (2006).

9) J. Zhang, W. Liu, V. Schnitzler, F. Tancret and J. M. Bouler, Acta Biomater., 10, 1035-1049 (2014).

10) S. M. Barinov and V. S. Komlev, Inorg. Mater., 47, 1470-1485 (2011).

11) H. H. K. Xu, F. C. Eichmiller and P. R. Barndt, J. Mater. Sci.: Mater. Med., 12, 57-65 (2001).

12) Y. Zhang and H. H. K. Xu, J. Biomed. Mater. Res., 75A, 832840 (2005).

13) J. E. Barralet, T. Gaunt, A. J. Wright, I. R. Gibson and J. C. Knowles, J. Biomed. Mater. Res., 63, 1-9 (2002).

14) E. F. Burguera, H. H. K. Xu and L. Sun, J. Biomed. Mater. Res., 84B, 493-502 (2008).

15) T. Sawamura, Y. Mizutani, M. Okuyama and T. Kasuga, J. Mater. Sci.: Mater. Med., 25, 1631-1636 (2014).

16) T. Sawamura, Y. Mizutani, M. Okuyama, A. Obata and T. Kasuga, J. Ceram. Soc. Japan, 123, 59-61 (2014).

17) P. K. Mehta, Concr. Int., 21, 69-76 (1999).

18) C. Z. Li, N. Q. Feng, Y. D. Li and R. J. Chen, Cem. Concr. Res., 35, 867-873 (2005).

19) J. Visser, Particul. Sci. Technol., 13, 169-196 (1995).

20) M. Collepardi and M. Valente, In Malhotre VM, editor. American Concrete Institute: special publication, 8th CANMET/ACI International Conference on Superplasticizers and Other Chemical Admixtures in Concrete (2006) pp. 1-14.
21) B. Jiang, S. Zhou, H. Ji, B. Liao and H. Pang, Colloids Surf., A, 396, 310-316 (2012).

22) L. A. Dos Santos, R. G. Carrodeguas, A. O. Boschi and A. C. F. De Arruda, Artif. Organs, 27, 412-418 (2003).

23) C. U. Herborn, E. Honold, M. Wolf, J. Kemper, S. Kinner, G. Adam and J. Barkhousen, Invest. Radiol., 42, 58-62 (2007).

24) G. Deray, O. Rouviere, L. Bacigalupo, B. Maes, T. Hannedouche, F. Vrtovsnik, C. Rigothier, J. M. Billiouw, P. Campioni, J. Ferreiros, D. Davos, D. Alison, F. Glowacki, J. J. Boffa and L. Marti-Bonmati, Eur. Radiol., 23, 1250-1259 (2013).

25) X. Wang, J. Ye and H. Wang, J. Biomed. Mater. Res., 78B, 259-264 (2006).

26) T. Kokubo and H. Takadama, Biomater., 27, 2907-2915 (2006).

27) K. Takahashi, Y. Fujishiro, S. Yin and T. Sato, Ceram. Int., 30, 199-203 (2004).

28) N. Adachi, O. Sakurada and M. Hashiba, J. Soc. Inorg. Mater. Jpn., 12, 463-471 (2005) [in Japanese].

29) J. S. Reed, "Principles of ceramics processing", 2nd ed., John Wiley \& Sons, Inc, New York (1995) pp. 150-168.

30) J. C. Wang, C. L. Koa, C. C. Hung, Y. C. Tyan, C. H. Lai, W. C. Chen and C. K. Wang, J. Dent., 38, 158-165 (2010).

31) L. C. Chow, S. Takagi, P. D. Constantino and C. D. Friedman, Proc. MRS, 179, 3-24 (1991).

32) Y. Miyamoto, K. Ishikawa, H. Fukao, M. Sawada, M. Nagayama, M. Kon and K. Asaoka, Biomater., 16, 855-860 (1995). 